\title{
Medical migration and world health
}

\author{
Alan G Fraser Department of Medicine, University of Edinburgh
}

Everyone knows that British doctors are emigrating and that other doctors, mostly from the third world, are immigrating to Britain. Also everyone thinks that he knows the reasons why. However, the Edinburgh Medical Group thought the various reasons for this medical migration should be examined more closely, and held a symposium (Chairman, Professor A S Duncan, Professor Emeritus of Medical Education in the University of Edinburgh) to examine the causes for medical migration at the present time.

Medical teaching and practice is still basically as it has been developed in the West and so overseas doctors trained in Britain take with them not only the medical knowledge and skills but also the attitudes of the West when they return to their own countries. Consequently they wish to settle in the towns and practise as consultants when the real medical problems in many of the developing countries are those of a rural population needing health care rather than treatment in what have been called 'disease palaces'. As speakers made clear, a new responsibility must fall on those training doctors from overseas in the British medical schools to fit them not for the dream world of the sophisticated medical scene but for the realities of working in often badly equipped clinics and dealing with common conditions such as malnutrition and other problems of maternity and child health.

The symposium also included discussions as to why British doctors wished to emigrate. Money seemed to be the most compelling motive, but opportunities were being limited for their migration for economic and political reasons.

Finally, a look at the whole of the medical scene in Britain: perhaps the standard sought in Britain both by the doctor and the patient is too high and too individualistic. Events will show if this be true.

For years doctors have been accustomed to travel all over the world both to study and to practise medicine. Many wish this was still possible, but the horizons open to young graduates are contracting as more governments legislate to restrict medical migration. Doctors may object to these measures as an erosion of their fundamental rights, but they should first reflect how their actions influence the health of the populations which they serve.

The broad scale of medical migration is not in doubt. The World Health Organisation ${ }^{1}$ estimated in 1971 that 140000 physicians or 6 per cent of the world total were working outside the countries in which they were born or trained. Eighty-five per cent of these were in only four countries, namely, the USA, Canada, the United Kingdom and West Germany. Immigrant doctors come increasingly from relatively few countries, whose basic health needs are not satisfied.

The United Kingdom is almost unique as it is both a significant donor and recipient of medical graduates. In 1970, 21000 , or one in four, of all doctors in Britain had been born abroad, and at least 5000 British-born doctors were practising in foreign countries. Since 1900 the net loss of British doctors has been surprisingly constant, at between 250 and 400 each year.

\section{Health care problems of the developing world}

At the symposium, Third World health problems were vividly described by $\operatorname{Dr}$ G J Ebrahim, who is Senior Lecturer in Tropical Child Health at the Institute of Child Health in London, but was once the only trained paediatrician in Tanzania. His main thesis was that the training of doctors in developing countries bears little relation to the health needs of the population, and so doctors acquire inappropriate skills and attitudes which they can use only if they move elsewhere.

He quoted many examples to support his argument, and has described his solutions in an awardwinning paper. ${ }^{2}$

In Venezuela 45 per cent of the population is below the age of 14, and in Ghana children in this age group and women in the child-bearing years together constitute 67 per cent of the population. This percentage is common to most developing countries, but in a recent survey of the curricula of medical schools in South East Asia, tropical Africa and Latin America, Dr Ebrahim found that the entire period devoted to child health rarely exceeded one month. There was no integrated approach to maternal and child health.

In many African countries 80 per cent or more of the population live in rural areas, and in India 80 per cent of the population live in 570000 villages, but in both regions medical students are selected from affluent urban areas. Their westernized lifestyle has little in common with village life; students 
are not taught social anthropology or how to understand villagers' problems and so are quite unprepared for work there. (One participant in the symposium reported that students in Kuala Lumpur required a special orientation course after graduation to enable them to practise medicine in their own country.)

Some large African hospitals have special units for the emergency treatment of dehydrated babies, debilitated from prolonged gastroenteritis and malnutrition. This is often related to bottle feeding, promoted by skilful advertising and subtle social pressures, but the cost is highly significant. In the Sudan the equivalent of one third of the total health budget is spent on importing artificial feeds for babies, and in Tanzania a similar proportion would be needed if the incidence of breast feeding was to decline by only 20 per cent. Yet Dr Ebrahim found in 10 medical schools in tropical Africa and India that on average only one hour was spent teaching students about breast feeding. Much more attention was devoted to the selection, preparation and sterilization of artificial milk.

Developing countries can often afford to spend no more on health care than one hundreth of the amount spent on each person by developed countries. They need small, flexible and mobile health services based on the lowest tier of the health care pyramid, but instead are lumbered with top-heavy institutionalized structures centred on sophisticated teaching hospitals, or 'disease palaces' as they have been called by Halfdan Mahler, the Director General of the World Health Organization. One example is the Mulago Hospital in Uganda, which in 1965 swallowed more than 60 per cent of the total health budget of the country while catering for a minute proportion of its population.

Economic realities now present developing countries with a clear choice. For example, in Tanzania the same amount of money could provide one regional hospital of 200 beds, catering for 4000 inpatients and 400000 outpatient consultations per year, or pay for 15 rural health centres with a workload of ro 000 admissions and one million consultations. As in other third world countries there is a plentiful supply of labour, but inherited health services mimic the capital-intensive systems which only the West can afford. Medical students in 'disease palaces' are not sufficiently encouraged to study these problems, or taught how to assess priorities and use limited financial resources as efficiently as possible.

The curricula of medical schools in developing countries have some glaring omissions but to Dr Ebrahim the 'hidden curriculum' is just as important. Medical students emulate their teachers and acquire values which reflect their interests. Success and prestige are equated with specialist practice, and young doctors may have learned to attach more importance to a high standard of living than to the health needs of village communities.
Developing countries need generalists rather that specialists, but specialization is perpetuated wher students receive most of their teaching from consultants in teaching hospitals. They should b. taught in the villages, gaining increasing responsie bility from an early stage and working alongside medical auxiliaries. Indeed it can be argued thase there is a greater need for paramedical personnes than for doctors, as in many developing countries population expansion at 2 or 3 per cent per year outstrips the rate at which doctors are accumulating. This widening gap will have to be filled by other health workers. The role of the specialist in a thire world country is therefore primarily to teach specia skills to medical students and primary healt $\$$ workers, and only secondly to advise on particulais health needs and provide a specialist referrat service.

In many countries doctors are now required to work in rural areas for some years after qualifiying Frequently their working conditions are poor an living facilities basic, and they come to harbouf resentment towards the authorities who force then to work in such surroundings. As soon as possible they migrate back to the cities but these are oftem 'overdoctored', for example, in Kenya where theret is one doctor for about every 1000 inhabitants in Nairobi and one for 2000 in other urban areas, bu only one for every 45000 people in rural districts Opportunities for private practice are limited, and young doctors in search of a living and professionali satisfaction may have little option but to join the brain drain.

A few countries, such as South Korea and the Philippines, have accepted medical migration as fact of life, and now deliberately produce more doctors than they need. Thus in 197140 per cent of all Filipino doctors were working abroad. Howe ever, most third world governments are ne prepared to accept continued migration and the considerable financial burden which it entails, but their legislation will fail to curb the exodus unless $f$ tackles the underlying disease rather than its symptoms. Doctors have already demonstrated the prowess at finding loopholes in restrictive regular tions.

In Sri Lanka doctors are compelled to work in the country for five years after graduation, so now medical students emigrate after the final examinax tions but before the results are announced. ${ }^{3}$ Ind no longer recognizes British postgraduate qualificas tions, and has banished the American Educational Council for Foreign Medical Graduates (ECFMG examination, so now Indian doctors travel to Kual Lumpur to sit this test. In Thailand a new medicaf school was built in the north at Chiang Mai, in a area which had relatively few doctors, but the entire initial output of graduates chartered an aircraft ang departed to the USA. 
Imposition of western systems of medical education and health care on the rest of the world

Professor A S Duncan, chairman of the symposium and Professor Emeritus of Medical Education at Edinburgh University, felt that the West bore a considerable responsibility for having imposed its system of medical education and health care on the rest of the world. Gifts of international aid to establish teaching hospitals are misguided and burden developing countries with massive running costs. Western solutions to health problems are often inappropriate, and established patterns of education cannot be transplanted wholesale. One speaker cited the medical curriculum in Dacca, which was modelled so closely on that in Edinburgh that it even included a 'special' tropical medicine course!

Overseas aid can have unexpected repercussions. During the sixties the Edinburgh medical school sent teams of medical teachers under the auspices of WHO to the Baroda Medical School in India, but a recent paper in a British journal, Medical Education, ${ }^{4}$ reported that between 1966 and 1972 50 per cent of Baroda's medical graduates went abroad. About I5 per cent of those who went to the UK subsequently returned, but more than threequarters went to the USA and only one of these doctors had returned when the study was undertaken. It is pertinent to ask whether the ultimate effect of the WHO scheme was beneficial to that community.

Some despondency was expressed about whether real change was possible, short of advocating a revolution, as those countries which recognized the basic problems had extreme difficulty in overhauling their health care systems. President Nyerere set forward his socialist principles for Tanzania at Arusha in 1965, but in 1971 the curative hospital services still consumed 79 per cent of the health budget compared with 80 per cent a decade before. However, an encouraging development was reported from Cameroon, where WHO has conducted a detailed study of the health needs of the population. On the basis of the results, appropriate health services are being developed, and a new medical school with a new curriculum is being established. It is hoped that this will be the forerunner of many similar developments elsewhere.

\section{The role of British doctors in training overseas graduates}

The focus of attention then turned to the role of British hospitals and teaching centres in the training of overseas graduates. The subject was introduced by $\mathrm{Mr}$ John Cook, now a consultant surgeon in Edinburgh and Secretary of the International Federation of Surgical Colleges, but formerly reader in surgery at the University of East Africa in Uganda.
A small minority of visiting doctors come to learn a new technique or compare aspects of British medicine with their own. These doctors have a clear objective and present no problem. In contrast the great majority come to acquire a postgraduate diploma which will enable them to return home to practise competitively as specialists, or else to migrate around the world with their qualification as a passport to professional freedom. Mr Cook foresees more problems for this group as the status of these examinations is changing. For example, the Fellowship of the Royal College of Surgeons is becoming established as part of a highly structured specialist training programme, similar to schemes in other European Economic Community (EEC) countries, and conferral of the diploma indicates fulfilment of criteria for specialist registration. In order to pass, overseas candidates have to become more involved in British medicine, and the longer they stay in Britain the less likely it is that they will eventually return home.

The flow of medical immigrants is now restricted by the Temporary Registration Assessment Board. Since in 1976 only 36 per cent of the 1420 candidates passed their examinations, $\mathrm{Mr}$ Cook thought that scrutiny of these doctors should not end there. At the last sitting of the first part of the FRCS examination, only 15 per cent of the 470 candidates succeeded, representing an appalling waste of time and expenditure on both sides. He thought greater efforts should be made to assess the educational background of doctors presenting themselves for the examination, so that some could be discouraged from sitting it. There should also be special counselling of candidates who fail repeatedly.

At present postgraduates are largely self-selected and ignored. Courses could be better tailored to their needs, and training requirements for the UK stipulated as prerequisites for the granting of specialist qualifications could be altered and reduced for overseas candidates, without compromising examination standards. Special courses could be provided for overseas doctors to attend before returning home, where they could learn how to teach, and how to undertake simple research projects to determine the most efficient way to apply their valuable professional skills to the solution of health problems.

\section{Emigration of doctors from Britain}

The final topic to be discussed in depth was the emigration of doctors from the UK. Mr Paul Vickers warned that opportunities for migration within the EEC might be limited, as the number of doctors in the Community was projected to increase from 354000 in 1970 to 526000 in 1985 , and some continental countries already had medical unemployment. Also doctors no longer have unrestricted 
access to traditional destinations such as Australia, New Zealand and North America.

Oscar Gish 5,6,7 has shown that most doctors who emigrate from the UK have spent several years in the health service before leaving. They tend to be senior registrars or junior consultants, who cite professional dissatisfaction and lack of opportunity as their main reason for leaving. Officials of the Scottish Home and Health Department now interview doctors who emigrate from career grades of the National Health Service, and they have found money to be the single factor mentioned most frequently. It would appear that the motives of British doctors who emigrate may be very similar to those of doctors who come to the West from developing countries.

Some thought-provoking local statistics were presented by Dr T A S Buist, a consultant radiologist at the Royal Infirmary of Edinburgh, who works for one month each year in Toronto. Within only four years 12 British-born radiologists, including two consultants and seven senior registrars, have emigrated from his department to North America. He thought that the main reasons were the greater status of the profession in Canada and the USA, higher incomes, better working conditions and much greater professional freedom. In addition he sensed a growing frustration amongst British doctors that their lot within the NHS was unlikely to improve, since unwieldy administration and limited resources hinder attempts to prevent standards from declining any further. Nevertheless the UK did have some advantages, particularly in job security and family life, and there was much truth in the axiom that after a doctor has crossed the Atlantic once, then he is always living on the wrong side. Changes in career structures might halt the trend.

\section{Are medical values in Britain wrongly directed?}

Ian Thompson, a philosophy lecturer now working as research fellow for the Edinburgh Medical Group, attempted to draw the various strands of thought together. He postulated that the root of the problem lay in the highly individualistic values of modern medicine, enshrined in the pursuit of excellence, the importance of professional self-fulfilment, and the responsibility of a doctor to his individual patient rather than to the community. This set of presuppositions had been exported to third world countries, but he challenged doctors to review whether these values are in fact the best and those most likely to improve world health. More universal values relating to the needs of society rather than of individuals were probably more appropriate, a society might be entitled to impose them on the profession.

Mr Cook and Professor A P M Forrest both sâw an inevitable conflict for doctors between their accustomed role of caring for individual patients afd their broader responsibilities to consider sockil values and community health. Professor Forrest wondered if standards of health care in the Uth might even be too high, and Mr Cook spoke of the unsolved ethical dilemma of what individual doctors should do when they know that the treatment whigh they can offer will be substandard, or less than the best which they have been trained to provide, but unavoidable on economic grounds and possibły justifiable on social grounds. Minimum acceptable requirements may be needed rather than optimuith (unattainable) standards.

It is easy to be cynical and dismiss all medical migration as inevitable, due to the self interest of doctors for greater personal and financial rewar $\$$, and equally glib to ignore the problem because ${ }_{0}$ f the multitude of economic and political factofs which create the climate in which migration flourishes. In spite of Virchow's dictum thet 'politics is nothing else but medicine on a large scale', the participants in this symposium did ngt set themselves the task of reforming the internation 1 political system but wisely chose a middle cours They drew a vital distinction between reversibge medical migration, which is potentially benefic? in many ways, and irreversible medical emigration, particularly from developing to developed countrie which can cause patients' interests to suffer.

\section{References}

${ }^{1}$ World Health Organization, Health Manpower Dievelopment, Part III: Progress report on the multinational study of the international migration of physicians and nurses, Geneva, 1976.

${ }^{2}$ Ebrahim, G J. A model of integrated community healoh care: Community health care in a rural area, Tropieal and Geographical Medicine, 1976, 28, 1, S5.

${ }^{3}$ Senewiratne, B, Emigration of doctors: A problem for the developing and the developed countries. Pafs I and II, British Medical fournal, 1975, 1, 618-620 and 669-67I.

${ }^{4}$ Bhatt, R V, Soni, J M, Patel, N F, and Doctor, P\&્ Migration of Baroda medical graduates, 1949Medical Education, 1976, 10, 290-292.

${ }^{5} G i s h, \mathrm{O}$, Doctor Migration and World Health. G Bellifs Sons, London, 1971.

-Gish, O, Medical brain drain revisited, Internationd fournal of Health Services, 1976, 6, $231-7$.

${ }^{7} \mathrm{Gish}, \mathrm{O}$, and Godfrey, $\mathrm{M}$, Why did the doctor crofs the road? New Society, 1977, 39, 539-540. 